\title{
PENDIDIKAN AGAMA HINDU DALAM PERKEMBANGAN BUDHI PEKERTI
}

\author{
Lilik $^{1}$ \& Juniarthi ${ }^{2}$ \\ ${ }^{1,2}$ Institut Agama Hindu Negeri Tampung Penyang Palangkaraya \\ bawiayahfda@gmail.com
}

\begin{abstract}
Riwayat Jurnal
Artikel diterima :-

Artikel direvisi : :

Artikel disetujui :-
\end{abstract}

\begin{abstract}
Abstrak
Pembangunan nasional baik yang telah, sedang, dan yang akan dilaksanakan tidak terlepas dari nilai-nilai keagamaan yang dijunjung tinggi dalam ajaran agama Hindu. Dalam pembangunan nasional pemerintah Indonesia melaksanakan penataan kehidupan beragama dan juga kepercayaan terhadap Tuhan Yang maha Esa yang lebih harmonis, hal ini tercermin dalam makin meningkatnya keimanan dan ketaqwaan terhadap Tuhan Yang maha Esa makin meningkatnya kerukunan kehidupan umat beragama dan penganut kepercayaan terhadap Tuhan Yang Maha Esa dan makin meningkatnya peran serta umat dalam pembangunan melalui pendidikan baik di lingkungan keluarga, masyarakat dan sekolah.Sebagai warga negara yang beragama Hindu dan hidup dalam negara Pancasila, dalam mengamalkan dan meyakinisuatu agama tidak boleh berpandangan sempit umat Hindu senantiasa harus menyesuaikan diri dengan lingkungan sekitarnya. Masyarakat Indonesia adalah masyarakat yang majemuk yang memeluk berbagai agama, oleh karena itu dalam mengamalkan ajaran agama yang baik pasti menghormati pula umat beragama yang lain. Umat Hindu harus berpandangan luas sehingga tidak menimbulkan fanatisme agama yang sempit, harus benar-benar konsekuen.
\end{abstract}

Kata Kunci: Pendidikan Agama Hindu, Budhi Pekerti

\section{PENDAHULUAN}

Pendidikan pada dasarnya merupakan usaha untuk membantu dan mengarahkan manusia agar berkembang sampai pada titik maksimal. Hal ini sesuai dengan tujuan pendidikan yang dicita-citakan seperti yang tercantum dalam UU RI No.20 Tahun 2003 tentang
Sistem Pendidikan Nasional yang menyatakan bahwa:

Pendidikan adalah usaha sadar dan terencana untuk mewujudkan suasana belajar dan proses pembelajaran agar peserta didik secara aktif mengembangkan potensi dirinya untuk memiliki 
kekuatan spiritual keagamaan, pengendalian diri, kepribadian, kecerdasan, ahlak mulia serta keterampilan yang diperlukan dirinya, masyarakat bangsa dan Negara ( Tim, 2003: 4).

Berdasarkan kutipan tersebut jelas bahwa titik sentral segala aktivitas pendidikan yakni bertujuan untuk meningkatkan kualitas sumber daya manusia, agar oleh tumbuhnya generasi bangsa yang terampil, maju, cerdas, tangguh, berdisiplin, beretos kerja, profesional, mandiri, serta bertaqwa terhadap Tuhan Yang Maha Esa dalam kondisi sehat jasmani dan rohani.

Tujuan pendidikan nasional tersebut selaras dengan tujuan pendidikan agama Hindu. Pendidikan Agama Hindu bertujuan:

1) Menumbuh kembangkan serta meningkatkan kualitas sraddha dan bhakti melalui pemberian, pemupukan, penghayatan dan pengamalan Agama;

2) Membangun insan Hindu yang dapat mewujudkan nilai-nilai MoksarthamJagathita $\mathrm{Ya} \mathrm{Ca}$ Iti

Dharma dalam kehidupannya (Tim Penyusun, 2007: 1-2).

Dalam Pembangunan dibidang Agama sasaran yang ingin dicapai adalah tercapainya suasana kehidupan beragama dan kepercayaan terhadap Tuhan Yang Maha Esa, yang penuh keimanan dan ketaqwaan, penuh kerukunan yang dinamis antar dan antara umat beragama dan kepercayaan terhadap Tuhan Yang Maha Esa secara bersama-sama makin memperkuat landasan spritual, moral dan etika bagi pembangunan nasional yang tercermin dalam suasana kehidupan yang harmonis serta dalam kukuhnya persatuan dan kesatuan bangsa selaras dengan penghayatan dan pengamalan Pancasila.

Fungsi ini biasa tampak melalui perilaku dan perbuatan seluruh umat Hindu bersama lembaganya dalam proses pembangunan. Peran yang bisa dimainkan ini tergantung sejauh mana umat Hindu memiliki kedalaman tentang agama yang dianut hubungannya denga konsep pembangunan yang dilaksanakan dengan pengetahuan diperoleh gambaran tentang potensi umat akan bisa dikembangkan agar fungsi agama benar-benar bisa terkemuka dalam pembangunan.

Pembinaan umat Hindu melalui pendidikan formal maupun non formal, di jalur formal diusahakan adanya guru-guru agama dan dosen agama sesuai kebutuhan, buku pendidikan, pelayanan pendidikan, agama melalui sekolah dan koordinasi dalam pengelolaan Perguruan Tinggi Agama Hindu, pendidikan agama non formal perlu ditingkatkan.

Adapun upaya peningkatan budhi pekerti dapat dilaksanakan melalui usaha maningkatkan ketaqwaan kepada Tuhan Yang Maha Esa, menumbuhkan kesadaran berbangsa dan bernegara, mempertebal idealisme dan harga diri serta semangat patriotisme, memperkokoh kepribadian dan disiplin, mempertinggi budi pekerti memupuk kesegaran jasmani dan rohani serta dapat mendorong partisipasi dalam kehidupan berbangsa dan bernegara. 
Dalam pelaksanaan pembangunan nasional hal ini berarti ilmu pengetahuan dan ketrampilan tidak cukup, tapi lebih penting adalah agar generasi muda dibekali dengan norma dan etika dalam kehidupan bermasyarakat, berbangsa dan bernegara yang bersumber dari Pancasila dan menanamkan nilai agama diharapkan dapat mengembangkan kepribadian yang baik.

Pendidikan agama Hindu sangat penting bagi kehidupan manusia, agama menuntut semangat hidup memberi motivasi hidup terhadap manusia. Memberi rambu-rambu kehidupan menuju kehidupan yang lebih baik dan mengajarkan kepada manusia untuk meyakini adanya wahyu Tuhan. Agama memberi petunjuk tentang hubungan manusia dengan manusia, hubungan manusia dengan alam, manusia dengan Tuhan sehingga terjadi kesadaran, keserasian dan keharmonisan.

Kebenaran agama adalah mutlak, kekal dan abadi yang merupakan kebenaran Tuhan yang bersifat gaib tidak terpikirkan oleh akal, secara konseptual kebenaran agama terletak pada suatu kepercayaan kepada Tuhan Yang Maha Esa, maka oleh sebab itu kebenaran dan kepercayaan terhadap kebenaran agama disebut orang beriman, iman (sradha) adalah suatu kepercayaan dan keyakinan yang berkenaan dengan agama.

Semua pendidikan yang diberikan di sekolah bertujuan membentuk manusia yang cakap, pandai dan berbudhi pekerti yang luhur serta memperkuat keyakinan beragama. Untuk membentuk anak yang berbudhi pekerti seorang guru mempunyai peranan yang utama di sekolah dalam menanamkan budhi pekerti anak didik, seorang guru terlebih dahulu harus menanamkan keyakinan beragama sebagai landasan dasar awal terlaksananya ajaran budhi pekerti.

Dalam pergaulan hidup ini, biasanya ada norma-norma yang harus mereka ikuti karena tanpa mengikuti norma-norma ini, lebih-lebih dalam eraglobalisasi ini pengaruh-pengaruh dari luar negeri yang tidak pantas atau kurang sesuai dengan kepribadian bangsa Indonesia dapat merusa anak didik yang merupakan pewaris bangsa, untuk inilah pentingnya peran pendidikan agama khususnya agama Hindu perlu diberikan kepada anak didik agar mereka mempunyai budhi pekerti yang luhur.

\section{PEMBAHASAN}

Budhi pekerti adalah sama dengan prilaku, dimana seorang siswa perlu ditanamkan tentang budhi pekerti yang baik. Penanaman budhi pekerti bisa dilakukan oleh orang tua, juga bisa melalui seorang guru agama Hindu yang mengajarkan mata pelajaran agama Hindu. Sebelum ditanamkan pada siswa didik seorang guru harus menanamkan budhi pekertinya pada diri sendiri yaitu dengan melalui sikap prilaku seorang guru sendiri diantaranya berpakaian yang rapi, bahasa yang sopan dan bertingkah laku yang baik, sesuai dengan normanorma seorang guru.

Menurut I Made Titib, (2003:1) bahwa budhi pekerti berasal dari bahasa 
Sansekerta yang terdiri dari dua kata yakni "budhi dan pekerti. Budhi yang artinya mengetahui kemudian berubah menjadi kata benda budhi yang berarti pengetahuan atau kecerdasan". Sedangkan dalam kamus besar bahasa Indonesia (1991:150) "budhi berarti alat batin yang merupakan paduan akal dan perasaan untuk menimbang baik dan buruk".

Pekerti berasal dari kata prakerti atau pravrti yang berarti prilaku. Dalam kosa kata bahasa Indonesia kata budhi dan pekerti disatukan dan memiliki satu pengertian yang tidak terpisahkan, yakni sebagai prilaku yang baik. Pendidikan budhi pekerti, mengandung makna usaha atau kegiatan yang mengantarkan seseorang anak menjadi dewasa dengan memiliki etika dan moralitas yang luhur, serta memiliki akhlak yang mulia.

Selanjutnya Sedyawati (dalam

Winata Putra, 2003:6) mengatakan bahwa budhi pekerti diterjemahkan dalam pengertian moralitas yang mengandung beberapa pengertian, antara lain adat istiadat, sopan santun dan prilaku. Selanjutnya di dalam kitab suci Panaturan pasal 41 ayat 40 yang mengatakan tentang ajaran budhi pekerti adalah yang berbunyi sebagai berikut

Tuntang tinai Bawi Ayah
maningak

Majar panakan utus Raja Bunu, bara

Ampin kare kutak pander, hadat basa,

Budi basara, maja marusik kulae bitie,
Uras mahapan hadat basara ije bahalap.

Artinya:

Setelah itu Bawi Ayah menasehati Mangajar anak turunan Raja Bunu,

Mulai dari tata cara berbicara, tingkah

Laku, sopan santun, tata cara bertamu

Ketempat keluarga, semuanya harus

Memakai tingkah laku yang baik.

(Majelis Besar Alim Ulama Kaharingan Indonesia, 1996:197)

Selanjutnya dalam buku Kandayu Basarah (penuntun persembahyangan) dari Kandayu Parawei Ayat 6 yang berbunyi :

Peteh mandehen Ranying Hatalla

Umba kalunen ije I nampa

Nyuang petak nguntep dunia

Ela mangawi taluh je papa.

Artinya:

Ranying Hatalla berfirman

Dengan umat manusia yang diciptakannya

Bagi manusia yang hidup di dunia ini

Hendaknya jangan melakukan perbuatan yang tidak baik.

(Majelis Besar Agama Hindu Kaharingan, 2001:17)

Dari kutipan di atas bahwa pendidikan budhi pekerti yang dimaksud adalah titik pijak, orientasi atau sudut pandang yang dijadikan acuan dalam menumbuh kembangkan pendidikan budhi pekerti sesuai ajaran agama Hindu. 
Dengan demikian seorang anak diantarkan menuju tingkat kedewasaan dengan prilakunya yang luhur sesuai nilai-nilai moralitas agama Hindu. Dalam pengertian yang lebih sederhana bahwa pendidikan budhi pekerti yang dimaksud adalah mengantarkan manusia menuju ke tingkat manusia yang memancarkan prilaku kedewasaan, arif bijaksana, lemah lembut, ramah dan manis tutur katanya.

Dalam pengertian yang luas bahwa pendidika meliputi usaha orangorang yang sudah dewasa, untuk mengalihkan pengetahuannya, pengalamannya maupun kecakapannya dan ketrampilannya kepada generasi muda, sebagai usaha untuk menyiapkan agar dapat memenuhi fungsi hidupnya baik jasmani maupun rohani. Dengan demikian, pendidikan bukan saja hanya berlangsung secara formal di sekolah saja, melainkan pada semua lingkungan sosialnya.

Tujuan pendidikan menurut agama Hindu juga tidak terlepas dari tujuan umum pendidikan nasional. Pada hakekatnya tujuan yang ingin dicapai oleh agama Hindu adalah hal-hal yang bersifat lahiriah dan bathiniah, yaitu lebih lanjut didalam penuntun belajar agama Hindu I (1994:9) dikatakan tujuan agama adalah "Moksartham Jagathita ya Ca Iti Dharma".

Dalam hal tersebut di atas jelas bahwa tujuan pendidikan budhi pekerti menurut agama Hindu di sekolah pada hakekatnya adalah sebagai berikut :

1. Pendidikan budhi pekerti Hindu di sekolah suatu upaya untuk membina pertumbuhan jiwa raga anak didik sesuai ajaran agama Hindu.

2. Membentuk manusia yang Pancasilais yang astiti bhakti (taqwa) kepada Tuhan Yang Maha Esa/Sang Hyang Widhi Wasa, dan membentuk moral etika dan spritual yang sesuai dengan ajaran Hindu

3. Didaktik dan metodik, pendidikan agama Hindu di sekolah disesuaikan dengan tingkat perkembangan jiwa anak didik :

a.Pendidikan agama Hindu dikorelasikan dengan bidang pendidikan lainnya.

b. Memberikan contoh-contoh kehidupan beragama yang baik (Ngurah, 1989:24).

Demikian pula halnya dalam agama Hindu, masalah pendidikan mendapat perhatian yang khusus, karena melalui pendidikan agama nantinya akan dapat membentuk pribadi manusia yang berbudhi pekerti yang luhur, dapat mengendalikan diri di tengah-tengah arus modernisasi dewasa ini, serta ilmu yang diperolehnya dapat dimanfaatkan sesuai dengan ajaran agama yang dipahami.. Kata wiweka berasal dari bahasa Sansekerta yang mengandung arti sikap sangat hati-hati dalam mempertimbangkan sesuatu edan memecahkan suatu masalah. Dalam hal ini ketetapan sikap perlu dimiliki guna memilih mana yang baik dan mana yang buruk atau mana yang benar dan mana yang salah. Kata Sad Ripu terdiri dari dua kata yaitu Sad dan Ripu, Sad artinya 6 
(enam), sedangkan Ripu berarti musuh. Jadi kata Sad Ripu berarti 6 (enam) musuh atau dengan kata lain berarti 6 (enam) jenis musuh yang berada pada setiap diri manusia. Kata Sad Atayayi terdiri dari kata Sad dan Atayayi, Sad artinya 6 (enam) dan Atayayi artinya kejam atau pembunuhan, jadi maksud Sad Atayayi adalah 6 (enam) macam pembunuhan yang kejam yang tidak patut dilaksanakan oleh manusia, karena hal ini sangat bertentangan dengan tujuan agama. Sedangkan Sapta Timira adalah tujuh macam kegelapan atau kemabukan yang gelap atau mabuk rupa tampan/cantik, kekayaan, kepandaian, keturunan/kebangsawan, keremajaan, minuman keras dan mabuk karena keberanian.

Sumber terjadinya perbuatan baik dan buruk adalah dari Tri Kaya parisudha yakni : mana, wakya, kaya, yaitu pikiran, perkataan dan perbuatan. Perbuatan atau karma baik dan karma buruk disebut dengan istilah Subha dan Asubha karma. Subha karma (perbuatan baik) menjadi sumber timbulnya kebahagiaan. Sebaliknya Asubha karma (perbuatan buruk) menjadi sumber timbulnya penderitaan atau kesengsaraan dan sejenisnya. Perbuatan baik bersumber dari Tri Kaya Parisudha yaitu tiga jenis perbuatan suci, yaitu : Manacika Parisudha, Wacika Parisudha dan Kayika Parisudha.

1. Yang timbul dari manah atau pikiran dalam kitab suci Saracamuscaya sloka 74 bunyinya demikian :
Anabhidhyam parswesu Sarwasatwesu Carusam

Karmanam phalamastiti

Triwidham manasa caret

Prawrttyaning manah rumuhan ajarakena

Telu kwehnya pratyekanya, si tan engin

Dengkya ri drebyaning len sitan krodha

Ring sarwa sattwa, si mamituhwa ri hananing karmaphala, nahan

Tang tiga ulahing manah,

Kartaning indriya ika.

Artinya :

Sifat hakekatnya pikiran (manah) yang pertama-tama akan diajarkan tiga banyaknya, perinciannya : tidak menginginkan dan dengki terhadap milik orang lain, tidak marah kepada sesama makhluk, percaya akan kebenaran ajaran karma phala, itulah ketiga bentuk sifat pikiran sebagai pengendali terhadap Panca indria itu. (Kajeng, 1997:64)

2. Yang tidak patut timbul dari wak (perkataan)

Menurut perkatan Saracamuscaya Sloka 75 disebutkan demikian :

Asatpralapan parusyam anartam tatha,

Catur wari waca rajendra na jalpenanucintayet.

Nihan tanpa prawrttyaning wak, pat kwehnya,

Pratyekanya, ujarahala, ujar aprgas, ujar pisuna, 
Ujar mitya, nahan tang pat singgahaning wak,

Tan ujarkena, tan angen-angen kojaranya.

Artinya :

Inilah yang tidak patut timbul dari perkataan (wak), empat banyaknya, masing-masingnya : perkataan jahat, perkataan kasar, perkataan yang memfitnah dan perkataan yang bohong, itulah keempatnya supaya dijauhkan dari kata-kata itu, jangan diucapkanpun juga tidak terpikirkan untuk diucapkan. (Kajeng, 1997:65).

3. Yang tidak patut timbul dari kaya (perbuatan) berdasarkan kitab Saracamuscaya Sloka 76 disebutkan demikian :

Pranatupatamstaiyam ca

Paradaranathapi wa,

Trini papani kayena sarwatah

Pariwarjawet

Nihan yang tan ulahkena, syamatimati

Manghalahala, si para dara, nahan tang telu

Tan ulaha kena ring asing ring parihasa ring apatkala

$R i$ pangipyan tuwi singgahana jugeka

Artinya :

Inilah yang tidak patut kita lakukan membunuh, mencuri, berzina, ketiganya itu jangan hendaknya engkau lakukan terhadap siapapun, baik secara berolok-olok, bersenda gurau, dalam keadaan dirundung malang, bahkan dalam keadaan mimpipun hendaknya supaya dihindari ketiganya. (Kajeng, 1997:66)

Berdasarkan ketiga sloka tersebut di atas dapatlah disimpulkan bahwa kita hendaknya selalu waspada dan selalu mengendalikan diri agar menjadi orang yang baik, hidup tenang, damai tentram, bahagia dan mansyur di dunia.

Lebih lanjut dapat kita lihat kegiatan pendidikan di dalam agama Hindu, dikenal dengan istilah "aguronaguron. Pengertian pendidikan dalam agama Hindu, tidak akan lepas dari kedudukan kitab Veda sebagai sumbernya. Oleh karena itu kitab Veda dan susastra Hindu lainnya berfungsi sebagai pedoman yang menuntun manusia dalam menjalankan kegiatan sehari-hari, termasuk dalam kegiatan pendidikan. Seperti yang dikutipkan dalam Sarascamuscaya Sloka 159-160 yang berbunyi :

Cilena hi tryo cakya jetum na sancayah,

$\mathrm{Na}$ hi kincidasadhyam vai loke cilena niccitah

Artinya :

Sebab tri loka inipun pasti akan kalah dan dikuasai oleh orang yang berketetapan hati melaksanakan kesusilaan, karena tidak ada sesuatu yang tidak tercapai oleh orang yang berprilaku susila. (Kajeng, 1997:127). 
Cilam pradhanam puruse tadyasyeha pranacyati, na tasya jivitenartho duhcilam kinprayojanam.

Cila ktikang pradhana ring dadi wwang, hana prawrttining

Dadi wwang duccila, aparan ta prayojananika ring hurip,

Kabeh, yan tan hana cilayukti.

Artinya :

Susila itu adalah yang paling utama (dasar mutlak) pada titisan sebagai manusia. Jika ada prilaku (tindakan) titisan sebagai manusia tidak susila, apakah maksud orang itu dengan hidupnya, dengan kekuasaan, dengan kebijaksanaannya, sebab sia-sia itu semua (hidup, kekuasaan, dan kebijaksanaan) jika tidak ada penerapan kesusilaan atau budhi pekerti yang luhur. (Kajeng, 1997:127).

Adapun pendidikan budhi pekerti yang perlu ditanamkan untuk anak didik antara lain : a) menanamkan sradha (keimanan) dan religiositas. b) berbhakti kepada kedua orang tua, c) mencintai dan menghormati guru, d) mencintai dan menghormati saudara, kakak dan adikadik, e) mencintai dan menghormati sahabat dan teman-teman, f) mencintai tanah air dan bangsanya, g) bersikap ramah dan berbicara manis, h) mengembangkan kebajikan, i) mengembangkan kesucian hati, j) taat sembahyang dan rajin belajar, k) kebenaran, pengorbanan dan kegiatan yang benar, 1) kedamaian dan kesabaran. (Titib, 2003 :102)

Memahami uraian di ataas dapat dinyatakan bahwa tujuan pendidikan budhi pekerti Hindu adalah membentuk manusia yang susila, bertanggung jawab serta taat melaksanakan ajaran agama, yang dibantu oleh guru agama Hindu dan ditunjang oleh pendidikan lainnya. Nilainilai kesusilaan mendapat tempat yang paling penting dibandingkan dengan nilai-nilai yang lainnya. Oleh karena itu maka tujuan tujuan pendidika agama Hindu tetap berlandaskan atas pembentukan kepribadian yang luhur dan budhi pekerti yang tinggi. Sehingga manusia mendapatkan kebahagiaan lahir maupun bathin. Wujud kebahagiaan lahir adalah terjaminnya kesejahteraan hidup di dunia ini berupa ketentraman, keamanan serta kedamaian hidup Jagathita.

Menjadi aspek moralitas dari ajaran agama Hindu sebagai sumber pendidikan budhi pekerti. Pendidikan agama hendaknya dipancarkan dalam budhi pekerti anak didik, baik didalam keluarga, sekolah maupun dalam masyarakat. Menjadikan pendidikan agama, khisusnya pendidikan moralitas dalam agama sebagai bagian yang terintegrasi dalam kurikulum pendidikan. Hal ini berarti pendidikan agama tidak hanya disampaikan oleh para guru agama Hindu di sekolah, tetapi juga semua pengajar dalam disiplin ilmunya masingmasing menunjang pendidikan budhi pekerti.

Upaya meningkatkan nilai-nilai budhi pekerti pada siswa dapat dilakukan 
dengan mengadakan pembinaan terhadap Umat Hindu dititikberatkan pada kegiatan-kegiatan yang menyentuh. Adapun kegiatan yang dimaksu terdiri dari :

1. Melakukan Doa dan Sembahyang

Berbagai bentuk dan aktivitas keagamaan adalah merupakan pengamatan ajaran Agama dalam rangka meningkatkan kesejahteraan dan kualitas spritual umat manusia. Salah satu usaha yang perlu dilaksanakan.

Doa adalah suatu usaha yang amat sederhana dan bila dilaksanakan secara sungguh-sungguh akan memberikan pahala yang besar. Tentang pahala dari doa yang khusuk sebagai salah satu wujud bhakti dalam Bhagawad Gita IX Sloka 22 :

Ananyas cintayo mam

Je janah paryupasate

Tesam niyabhiyuktanam

Yogasekmamvatamy aham.

Artinya :

Sebaliknya mereka yang tidak mengerti makna kehidupan dalam dirinya tidak bersemi rasa bhakti, tidak mensyukuri arti penjelmaan ini tidak ikhlas menghadapi persoalan hidup dan mencari sesuatu tidak berdasarkan dharma malas hanyut oleh emosi, ambisi dan nafsu.

Dari sloka di atas dijelaskan bahwa untuk menghindari dari berbagai cobaan dan ujian hidup seseorang harus berpegang, memahami, dan mempedomani serta mengamalkan ajaran agama dengan baik, mengembangkan kasih, sayang, jujur, hormat kepada orang tua dan guru, menghindari diri dari segala perbuatan tercela, tekun melakukan sembahyang dan rajin berdoa.

Sembahyang adalah suatu usaha/cara yang akan dilakukan untuk mendekatkan diri kepada Tuhan Yang Maha Esa, menyerahkan diri, pengabdian, dan melakukan kerja tanpa apapun secara ikhlas serta memberikan kebahagiaan tersendiri.

2. Mengadakan Kelompok Belajar

Kelompok belajar adalah kegiatan belajar dan mengajar dilaksanakan dalam jangka waktu tertentu tergantung pada warga belajar. Program belajar dapat berupa paket-paket dan disusun bersama dan diatur antara warga belajar dan sumber belajar. Sumber belajar dapat berperan sebagai pembina dan pendidik dalam kegiatan kelompok belajar. Sebagaimana dalam kitab canakya Nitisastra Bab II Sloka 13 (1994:14) yang berbunyi :

Slokena va tadardhena
tadaddharddaksarenava
avandhyam divasam kuryad
danadhyayana karmabhih.
Artinya :
Isilah waktu setiap hari dengan
menghapalkan satu sloka 1 ayat
atau setengah sloka atau
seperempat sloka atau satu huruf
dari sloka tersebut. Atau istilah
hari-hari anda dengan
bersedekah, belajar kitab suci
dan kegiatan bermanfaat
lainnya.

3. Mengadakan Kerja Bhakti 
Kerja bhakti adalah umat Hindu melaksanakan kegiatan gotong royong untuk membersihkan tempat suci, saling tolong menolong bila umat Hindu melaksanakan upacara yajna tanpa mengharapkan imbalan/pamrih.

Seperti dalam kitab Bhagawad Gita Bab III Sloka 19 (1997:172) yang berbunyi :

Tasmad asaktah satatam
karyam

Karma samacara

Asakto hy acaran karman param

Apnoti purusah.

Artinya :

Oleh karena itu laksanakanlah segala kerja sebagai kewajiban tanpa terikat sebab kerja yang bebas dari keterikatan, bila melakukan pekerjaan orang itu akan mencapai tujuan yangtertinggi.

4. Mengunjung Tempat-tempat Suci

Dalam rangka peningkatan keimanan dalam Agama maka umat Hindu melakukan kunjungan ke tempat suci tempat bersejarah Agama Hindu serta mempererat dan menjalin tali persaudaraan dengan saling kunjung sesama umat Hindu. Hal ini sejalan dengan sloka 277 Kitab Sarasamuccaya (1994 :217) yang berbunyi sebagai berikut :

Hana ya Wang mangke kramanya, tan kataman krodha satya ta ya, apageh ta ya ring brata. Masih rin sarwa sattwa ri hidepnya, ikang wang mangkana
krama-Nya phahalaning tirthayatra katemu denika dlaha tirthyatra ngaraning mahas agelem atirtha.

Artinya :

Adalah orang yang seperti ini perilakunya, tidak kerasukan marah tapi mencintai kebenaran tetap teguh pada brata, kasih sayang terhadap segala makhluk karena tidak berbeda dengan makhluk lain pada perasaannya, orang yang demikian perilakunya pahala tirthayatra diperolehnya kemudian.

5. Latihan Membaca Kitab Suci

Dalam rangka menciptakan tiga kondisi ideal yaitu peningkatan sradha, pemahaman isi kitab suci dan juga memelihara kerukunan hidup beragama maka sangat tepat sekali bila di lingkungan siswa diadakan latihan membaca kitab suci, sebagaimana dalam Bab IV Sloka 1 Canakya Nitisastra (1992 : 91) yang berbunyi :

Sruta dharmam vi janati sruta tyajati darmatim sruta jnanamavapnoti sruta moksa mavapnuyat.

Artinya :

Setelah membaca dan mendengar Weda orang biasa mengerti dharma, dengan mendengarkan Weda pikiranpikiran buruk bisa dihilangkan, dengan mendengarkan Weda orang bisa betul-betul dapat memperoleh ilmu pengetahuan, hanya dengan mendengarkan 
Weda orang bisa mendapatkan pembebasan.

\section{Dharma Wacana}

Dharma wacana adalah metode penerangan Agama Hindu ceramahceramah yang disampaikan secara umum pada umat Hindu untuk meningkatkan pengetahuan dan pengamalan serta penghayatan ke dalam rohani umat serta mutu amal bhaktinya kepada agama dalam usaha meningkatkan dharma agama. Hal ini sangat tepat dilakukan sesuai dengan Kitab Yajur Weda XXVI. 2 :

Yathenam vacam kalyanim

Awadanijanebhayah, brahma, rajanyabhyam

Sudraya caryaya ca svaya caranaya ca.

Artinya :

Hendaknya disampaikan sabda suci ini kepada seluruh umat manusia, cendikiawan, rohaniawan, raja, pemerintah/masyarakat, para pedagang, dan petani serta nelayan para buruh, kepada orang-Ku dan orang asing sekalipun.

Dari sloka di atas dijelaskan bahwa Agama Hindu itu merupakan agama misi yang harus disebarluaskan karena keluhuran ajaran Hindu. Orang-orang merasa tertarik untuk mendalami dan mengikutinya.

7. Merayakan Hari Raya Agama

Hari raya adalah hari yang dianggap suci, hari raya merupakan tonggak penyucian diri, merupakan ungkapan rasa bhakti kepada-Nya. Rasa bhakti ini diwujudkan dalam bentuk persembahan sesajen yang diiringi doa-doa itu mengandung dua hal yaitu :

1). Unsur pujian yang berarti memuja, memuji untuk mengungkapkan kebesaran Tuhan Yang Maha Esa atas segalanya.

2). Unsur permohonan yaitu memohon diberikan umur panjang, keselamatan, kesejahteraan, dijauhkan dari marabahaya.

Dalam rangka peningkatan sradha keagamaan anak maka sangatlah tepat bila perayaan hari raya keagamaan dilaksanakan yang tentunya melibatkan generasi muda baik dalam mempersiapkan sarana prasarana upacara maupun pada saat pelaksanaan upacara yang sedang berlangsung.

\section{Mengadakan Pendalaman Weda}

Pendalaman Weda adalah suatu usaha mempelajari Kitab Suci Weda. Usaha ini akan berhasil bila menguasai ilmu pengetahuan, seseorang yang telah membaca Weda tidak mengerti makna yang terkandung dalam matram-matram Weda, tidak memperoleh dan mendapatkan penerangan rohani seperti batang kayu bakar disiram minyak tanah, tidak pernah terbakar bila tidak terdapat api. Demikian orang yang hanya membaca tanpa mengetahui arti/makna matram Weda tidak memperoleh cahaya pengetahuan sejati. Hal ini diungkapkan dalam Sarasacamucaya Sloka 39 (1995:120) dikatakan : "penguasaan 
ajaran Kitab Suci Weda akan menjadi sempurna bila melalui Itihasa da Purana, Sebab Weda merasa takut kepada yang sedikit ilmunya, sabda-Nya kamu jangan mendekati Aku, sabda-Nya demikian karena rasa takut. Dengan demikian mendalami ajaran Weda akan mengantarkan seseorang untuk mencapai tujuan tertinggi, kesejahteraan dan kebahagiaan hidup.

\section{Menyediakan Buku-buku Agama Hindu}

Buku-buku Agama Hindu juga turut menunjang dalam upaya meningkatkan iman generasi muda karena dengan tersedianya buku-buku Agama Hindu maka semangat mempelajari hal-hal keagamaan akan selalu berkobar. Bila seseorang telah tertarik, dengan sendirinya akan percaya bahwa Agama Hindu adalah penuntun hidup yang benar dan dapat memberikan kedamaian jasmani dan rohani.

10. Mengadakan Latihan Memimpin Sembahyang

Sembahyang sangat perlu bagi umat Hindu tiap mengadakan sembahyang selalu membutuhkan seseorang pemimpin sembahyang. Selama ini untuk menjadi pemimpin dalam sembahyang adalah pendeta atau pedanda/pemangku/sulinggih. Agar kita tidak kehilangan generasi muda perlu ada tuntunan moral agar selalu aktif sembahyang karena dia merasa bahwa dirinya adalah calon pemimpin.

Hal tersebut sesuai dengan pendapat G. Pudja dalam isi kitab
Bhagavad-Gita (Pancama Weda), sebagai berikut:

Samniyamye 'ndriyagramam

sarwatra samabuddhayah,

te parapnuwanti mam ewa

sarwabhutahite ratah (BhagavadGita, XII.4).

Artinya:

Dengan mengendalikan panca indra,

Menganggap sama dalam segala pengertian,

Berusaha guna kesejahteraan semua insani,

Mereka sampai kepada-KU. (Pudja, 2003: 285)

\section{PENUTUP}

Dalam perkembangan budhi pekerti siswa ada beberapa faktor yang mempengaruhi seperti faktor keluarga, lingkungan masyarakat, dan pendidikan. Dewasa ini tantangan kehidupan beragama dirasakan semakin besar. Berbagai informasi, terutama yang bersifat duniawi langsung dan tidak kita sadari telah berproses dalam diri sebagai masyarakat kita. Kehidupan spritual mulai dirasakan kurang bermanfaat dan akibatnya adalah moral dan etika semakin mendangkal, dampaknya adalah terjadinya penyalahgunaan miras, pencurian dan kekerasan, serta berbagai penyakit sosial lainnya.

Untuk itu ada beberapa faktor untuk mengembangkan budhi pekerti siswa diantaranya :

1. Pada keluarga pendidikan budhi pekerti seperti halnya pendidikan 
agama pada keluarga rupanya perlu mendapat perhatian karena terjadinya pergeseran pola kehidupan masyarakat dari masyarakat agraris ke industri. Pendidikan budhi pekerti dalam keluarga cenderung terabaikan karena kehidupan beragama tekanannya pada ritual belum mampu mengubah prilaku masyarakatnya ke arah yang agamais.

2. Pada sekolah umum dan perguruan tinggi. Selama ini pendidikan budhi pekerti diberikan oleh guru agama, sebaliknya guru agama belum mendapat pendidikan atau metodologi khusus untuk menyampaikan pendidikan budhi pekerti yang bersumber pada ajaran agama. Disamping itu pendidikan budhi pekerti tidak terintegrasi dengan mata pelajaran diluar agama di sekolah. Hal ini mengakibatkan pendidikan budhi pekerti kurang mendapat perhatian.

3. Lembaga pendidikan non formal. Sangat terbatasnya pendidikan agama Hindu non formal misalnya pasraman, pasantrian dan kelompok pengkajian dan lainnya.

4. Pada lingkungan masyarakat. Pendidikan budhi pekerti pada masyarakat terkait dengan tegaknya norma dan moralitas masyarakat. Bila masyarakat heterogen dan cenderung permisif, maka sulit sekali untuk tegaknya norma dan moralitas masyarakat. Hal ini didukung oleh media masa yang kadang-kadang mengabaikan moralitas masyarakat seperti film barat yang nampak jauh dengan rasa budaya masyarakat.

Menjadi aspek moralitas dari ajaran agama Hindu sebagai sumber pendidikan budhi pekerti. Pendidikan agama hendaknya dipancarkan dalam budhi pekerti anak didik, baik didalam keluarga, sekolah maupun dalam masyarakat. Menjadikan pendidikan agama, khisusnya pendidikan moralitas dalam agama sebagai bagian yang terintegrasi dalam kurikulum pendidikan. Hal ini berarti pendidikan agama tidak hanya disampaikan oleh para guru agama Hindu di sekolah, tetapi juga semua pengajar dalam disiplin ilmunya masingmasing menunjang pendidikan budhi pekerti.

\section{DAFTAR PUSTAKA}

Bahridjamarah, Saiful dan Aswan Zain. 2002. Strategi Belajar Mengajar. Jakarta: Rineka Cipta.

Departemen Pendidikan dan Kebudayaan, 1991. Kamus Besar Bahasa Indonesia, Edisi kedua, Balai Pustaka.

Kajeng, I Nyoman, dkk. 1997. Sarasamuccaya. Surabaya: Paramita.

Mantra, I Bagus, 2003. Bhagawadgita Alih bahasa dan Penjelasan, Proyek Peningkatan 
Koordinasi Terhadap Umat Hindu di Luar Daerah, Denpasar

Majelis Besar Alim Ulama Kaharingan Indonesia, 1996, Panaturan, Palangka Raya

Ngurah, I Gusti Made, 1989. Pedoman

Guru Pendidikan Agama Hindu, Widya Dharma, Denpasar

Pudja,G. 2003. Bhagawad-Gita (Pancama Weda). Jakarta: Pustaka Mitra.

Riduwan, 2004. Statistika untuk Lembaga dan Instansi Pemerintah/Swasta. Bandung: Alpabet

Titib, I Made, 2003, Menumbuhkembangkan Pendidikan Budhi pekerti pada Anak,PHDI Pusat, Jakarta.

Winata Putra, H. Udin S, dkk, 2003. Pedoman Umum Pendidikan Budhi Pekerti Pada Jenjang Sekolah Dasar dan Menengah, Ditjen Diknasmen, Jakarta 